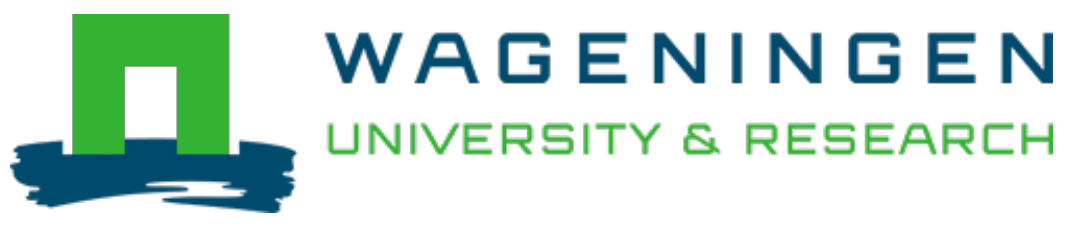

\title{
The diploid origins of allopolyploid rose species studied using single nucleotide polymorphism haplotypes flanking a microsatellite repeat
}

\author{
Journal of Horticultural Science and Biotechnology \\ Zhang, J.; Esselink, G.; Che, D.; Fougère-Danezan, M.; Arens, P. et al \\ https://doi.org/10.1080/14620316.2013.11512940
}

This article is made publicly available in the institutional repository of Wageningen University and Research, under the terms of article $25 \mathrm{fa}$ of the Dutch Copyright Act, also known as the Amendment Taverne. This has been done with explicit consent by the author.

Article 25 fa states that the author of a short scientific work funded either wholly or partially by Dutch public funds is entitled to make that work publicly available for no consideration following a reasonable period of time after the work was first published, provided that clear reference is made to the source of the first publication of the work.

This publication is distributed under The Association of Universities in the Netherlands (VSNU) 'Article $25 \mathrm{fa}$ implementation' project. In this project research outputs of researchers employed by Dutch Universities that comply with the legal requirements of Article $25 \mathrm{fa}$ of the Dutch Copyright Act are distributed online and free of cost or other barriers in institutional repositories. Research outputs are distributed six months after their first online publication in the original published version and with proper attribution to the source of the original publication.

You are permitted to download and use the publication for personal purposes. All rights remain with the author(s) and / or copyright owner(s) of this work. Any use of the publication or parts of it other than authorised under article $25 \mathrm{fa}$ of the Dutch Copyright act is prohibited. Wageningen University \& Research and the author(s) of this publication shall not be held responsible or liable for any damages resulting from your (re)use of this publication.

For questions regarding the public availability of this article please contact openscience.library@,wur.nl 


\title{
The diploid origins of allopolyploid rose species studied using single nucleotide polymorphism haplotypes flanking a microsatellite repeat
}

\author{
By J. ZHANG ${ }^{1,2}$, G. D. ESSELINK ${ }^{2}$, D. CHE ${ }^{1}$, M. FOUGÈRE-DANEZAN ${ }^{3}$, P. ARENS ${ }^{2}$ and \\ M. J. M. SMULDERS ${ }^{2 *}$ \\ ${ }^{1}$ Horticulture College, Northeast Agricultural University, No. 59 Mucai Street, XiangFang District, \\ Harbin 150030, Heilongjiang, P. R. China \\ ${ }^{2}$ Wageningen UR Plant Breeding, Wageningen UR, P.O. Box 16, NL-6700AA Wageningen, \\ The Netherlands \\ ${ }^{3}$ Chengdu Institute of Biology, Chinese Academy of Sciences, P.O. Box 416, Chengdu 610041, \\ Sichuan, P. R. China
}

(e-mail rene.smulders@wur.nl)

(Accepted 12 September 2012)

\begin{abstract}
SUMMARY
The taxonomy of the genus Rosa is complex, not least because of hybridisations between species. We aimed to develop a method to connect the diploid Rosa taxa to the allopolyploid taxa to which they contributed, based on the sharing of haplotypes. For this we used an SNPSTR marker, which combines a short tandem repeat (STR; microsatellite) marker with single nucleotide polymorphisms (SNPs) in the flanking sequences. In total, 53 different sequences (haplotypes) were obtained for the SNPSTR marker, Rc06, from 20 diploid and 35 polyploid accessions from various species of Rosa. Most accessions of the diploid species had only one allele, while accessions of the polyploid species each contained two-to-five different alleles. Twelve SNPs were detected in the flanking sequences, which alone formed a total of 18 different haplotypes. A maximum likelihood dendrogram revealed five groups of haplotypes. Diploid species in the same Section of the genus Rosa contained SNP haplotypes from only one haplotype group. In contrast, polyploid species contained haplotypes from different haplotype groups. Identical SNP haplotypes were shared between polyploid species and diploid species from more than one Section of the genus Rosa. There were three different polymorphic repeat regions in the STR region. The STR repeat contained eight additional SNPs, but these contributed little to the resolution of the haplotype groups. Our results support hypotheses on diploid Rosa species that contributed to polyploid taxa. Finding different sets of haplotypes in different groups of species within the Sections Synstylae and Pimpinellifoliae supports the hypothesis that these may be paraphyletic.
\end{abstract}

A consensus taxonomy of the genus Rosa was updated by Wissemann (2003) following the system of Rehder (1940). The updated system consisted of four subgenera: Hulthemia (one species), Platyrhodon (one species), Hesperhodos (two species), and Rosa (approx. 180 species). The sub-genus Rosa was further sub-divided into ten Sections: Rosa, Pimpinellifoliae, Synstylae, Laevigatae, Caninae, Carolinae, Cinnamomeae, Banksianae, Bracteatae, and Indicae. Caninae was the largest of these Sections and was further sub-divided into six sub-Sections. Considerable taxonomic confusion exists (Koopman et al., 2008), caused by extensive hybridisation between species (Wissemann and Ritz, 2005; Joly et al., 2006) leading to (i) segmental allopolyploids, (ii) an absence of clear morphological differences between many of the species (Wissemann and Ritz, 2005), and (iii) incomplete lineage sorting.

Several studies have used molecular markers and gene sequences to study genetic diversity and phylogenetics in the genus Rosa. Organellar DNA markers such as matK (Matsumoto et al., 1998; Wu et al., 2000; Leus et al., 2004) or atpB (Wissemann and Ritz, 2005), or nuclear DNA markers such as AFLP (Koopman et al., 2008) or short tandem repeat markers [STR; also called simple

*Author for correspondence. sequence repeat (SSR) or microsatellite markers; Esselink et al., 2003] have been used. An AFLP study by Koopman et al. (2008) provided the best-resolved dendrograms so far. AFLPs have also been used to clarify relationships in samples of dog-rose (De Cock et al., 2008). STRs have been used to estimate genetic diversity in varieties of hybrid tea rose (Smulders et al., 2009), $R$. damascena (Babaei et al., 2007), and R. foetida (Samiei et al., 2009), and to study taxonomic relationships among rose species (Scariot et al., 2006; Samiei et al., 2010). STR markers have some disadvantages for taxonomic studies, namely a high rate of mutation and the possibility that alleles back-mutate (homoplasy). However, Alvarez et al. (2001) concluded, from studies in tomato, that lowpolymorphic STRs which have a lower mutation rate, and probably fewer cases of homoplasy, contain useful phylogenetic information at the species level.

SNPSTR markers combine the presence of an STR with at least one single nucleotide polymorphism (SNP) or an indel (Mountain et al., 2002). These have different mechanisms and rates of mutation; but, as they occur close together in the same stretch of DNA, they share a genealogy and can easily be genotyped together (Mountain et al., 2002; Payseur and Cutter, 2006; Sorensen and DaCosta, 2011). Ramakrishnan and Mountain (2004) showed the power of SNPSTR markers 
as estimates of the time of divergence of human populations leaving Africa, based on STR variations, were more accurate and precise when the SNP background was included in the analysis.

Various standard molecular markers have not resolved classification issues in taxa derived from hybridisations between diploid taxa, as hybridisation merely leads to new combinations of genomes in the allopolyploids, with mixtures of morphological characters as well as DNA polymorphisms. One way to clarify the taxonomy of polyploid rose species is to analyse which diploid species formed the parental taxa for the polyploid taxa, as for example Griffin et al. (2011) did in Poa, and Brassac et al. (2012) did in Hordeum. We wanted to connect certain DNA fragments (haplotypes or alleles) of polyploid rose species to the corresponding DNA fragments in a putative parental diploid rose species. To do this, the locus must be sufficiently polymorphic between diploid species and, at the same time, the haplotypes must be sufficiently stable (i.e., have a low level of homoplasy) to be traceable from a diploid rose species to the allopolyploid derived from it. For example, based on alcohol dehydrogenase $(A D H)$ gene haplotypes, it was possible to conclude that the tetraploid $R$. gallica may have originated from an interspecific hybridisation between one Cinnamomeae species and one Synstylae species (O. Raymond, unpublished data; cited in Smulders et al., 2011). An SNPSTR marker may also fulfil these demands.

Our hypothesis was that SNPSTR alleles in diploid rose species could also be found in polyploids. If the same haplotype was found in diploid and polyploid species, this would support the contribution of a species from the sub-Section to which the diploid species belongs, to the polyploid genome. A proof-of-concept study was undertaken on the use of SNPSTR haplotypes to follow alleles in different taxa. Differences in STR lengths were convenient as uniquely-sized alleles that can be separated in polyacrylamide gels before sequencing, thus avoiding the need to clone all alleles.

\section{MATERIALS AND METHODS \\ Plant material and DNA extraction}

Fifty-five Rosa accessions, representing 20 diploid, 34 polyploid species, and one hybrid, from Iran, Switzerland, Germany, The Netherlands, and China, were included in this analysis (Table I). Genomic DNA was extracted from a single young leaf of each plant using the DNeasy Plant Mini Kit (Qiagen, Westburg, The Netherlands) and quantified using a Nanodrop spectrophotometer (Isogen, De Meern, The Netherlands).

\section{SNPSTR marker amplification}

An STR enrichment procedure was applied, as previously described (Esselink et al., 2003), directed at only trinucleotide repeat motifs in longer fragments (300 $-1,000 \mathrm{bp}$ ) instead of $250-700 \mathrm{bp}$ fragments. Among the cloned fragments was a single polymorphic STR of 413 bp, called Rc06 (EMBL/GenBank Accession Number HE608872). Amplification of Rc06 in each Rosa accession was performed in $20 \mu \mathrm{l}$ reaction mixtures, each containing $2.0 \mu \mathrm{l} 10 \mathrm{X}$ PCR polymerase buffer, $0.4 \mu \mathrm{l} 5$ $\mathrm{mM}$ dNTP, $0.4 \mu \mathrm{l} 10 \mathrm{pmol} \mathrm{ml}^{-1}$ of each primer, 0.3 Units
Goldstar Taq polymerase (Eurogentec, Liege, Belgium), $1.5 \mu \mathrm{MgCl}_{2}$, and $10 \mathrm{ng}$ DNA sample. The primers (Rc06F 5'-CTGGATCAGCTATTGTAGACTGC-3'; and Rc06R 5'-TGCTTCGGATCAGGGTTC-3') were designed using DNASTAR software (DNASTAR, Madison, WI, USA). The PCR programme consisted of an initial denaturation step at $94^{\circ} \mathrm{C}$ for $3 \mathrm{~min}$, followed by 35 cycles of $30 \mathrm{~s}$ at $94^{\circ} \mathrm{C}$, a ramp to $50^{\circ} \mathrm{C}\left(\right.$ at $\left.1^{\circ} \mathrm{C} \mathrm{s}^{-1}\right), 50^{\circ} \mathrm{C}$ for $30 \mathrm{~s}$, a ramp to $72^{\circ} \mathrm{C}\left(\right.$ at $1^{\circ} \mathrm{C} \mathrm{s}^{-1}$ ), and $72^{\circ} \mathrm{C}$ for $1 \mathrm{~min}$, with a final extension at $72^{\circ} \mathrm{C}$ for $7 \mathrm{~min}$.

The PCR products were mixed with an equal volume of formamide containing $10 \mathrm{mM} \mathrm{NaOH}$ and $0.05 \%(\mathrm{v} / \mathrm{v})$

TABLE I

Fifty-five accessions of Rosa species used in this study

\begin{tabular}{|c|c|c|c|}
\hline $\begin{array}{l}\text { Accession } \\
\text { Code No. } \mathbb{I}\end{array}$ & Species name & Location & $\begin{array}{l}\text { Ploidy } \\
\text { level }\end{array}$ \\
\hline 50 & R. acicularis Lindl. & - & 2 \\
\hline 22 & R. arvensis & Germany & 2 \\
\hline 23 & R. arvensis & Germany & 2 \\
\hline 39 & R. arvensis & - & 2 \\
\hline 44 & R. blanda Aiton & - & 2 \\
\hline 18 & R. caesia Nyman & Switzerland & 5,6 \\
\hline 2 & R. canina $\mathrm{L}$. & Iran & 5 \\
\hline 6 & R. canina $\mathrm{L}$. & Iran & 5 \\
\hline 11 & $R$. canina $\mathrm{L}$. & Switzerland & 5 \\
\hline 19 & R. canina $\mathrm{L}$. & Germany & 5 \\
\hline 27 & R. canina L. & Netherlands & 5 \\
\hline 28 & R. canina $\mathrm{L}$. & Netherlands & 5 \\
\hline 51 & R. chinensis 'spontanea' Jacq & China & 2 \\
\hline 14 & $R$. columnifera & Switzerland & 4 \\
\hline 34 & R. corymbifera & Netherlands & 5 \\
\hline 20 & R. corymbifera Borkh. & Germany & 5 \\
\hline 21 & R. corymbifera Borkh. & Germany & 5 \\
\hline 4 & R. damascene L. & Iran & 4 \\
\hline 15 & R. dumalis Bechst. & Switzerland & 5 \\
\hline 26 & R. dumalis Bechst. & Netherlands & 5 \\
\hline 5 & R. foetida 'double' Herrm. & Iran & 4 \\
\hline 3 & R. foetida Herrm. & Iran & 4 \\
\hline 9 & R. hemisphaerica Herrm. & Iran & 4 \\
\hline 40 & R. hugonis Hemsl. & - & 2 \\
\hline 1 & R. iberica Steven ex M. Bieb. & Iran & 5 \\
\hline 7 & R. iberica Steven ex M. Bieb. & Iran & 5 \\
\hline 13 & $R$. inodora & Switzerland & 5 \\
\hline 46 & R. majalis Herrm. & - & 2 \\
\hline 29 & R. micrantha Borr. ex Sm. & Netherlands & $4,5,6$ \\
\hline 41 & R. moschata L. & - & 2 \\
\hline 45 & R. multiflora ' 117 '* & - & 2 \\
\hline 37 & R. multiflora Thunb. & - & 2 \\
\hline 43 & R. nitida & - & 2 \\
\hline 10 & $R$. orientalis & Iran & 5 \\
\hline 48 & R. pendulina & - & 2 \\
\hline 8 & R. pimpinellifolia $\mathrm{L}$. & Iran & 4 \\
\hline 42 & R. roxburgii & - & 2 \\
\hline 35 & R. rubiginosa $\mathrm{L}$. & Switzerland & 5 \\
\hline 47 & R. rugosa Thunb. & - & 2 \\
\hline 53 & R. sericea Lindl. & China & 2 \\
\hline 54 & $\begin{array}{l}\text { R. sericea subsp. omeiensis } \\
\text { (Rolfe) A.V. Roberts }\end{array}$ & China & 2 \\
\hline 55 & $\begin{array}{l}\text { R. sericea subsp. omeiensis } \\
\text { (Rolfe) A.V. Roberts }\end{array}$ & China & 2 \\
\hline 49 & R. sertata Rolfe & - & 2 \\
\hline 16 & R. sherardii Davies & Switzerland & $4,5,6$ \\
\hline 31 & R. sherardii Davies & Netherlands & $4,5,6$ \\
\hline 24 & R. spinosissima L. & Germany & 4 \\
\hline 30 & R. spinosissima L. & Netherlands & 4 \\
\hline 25 & R. tomentella Léman & Netherlands & 5 \\
\hline 33 & R. tomentella Léman & Netherlands & 5 \\
\hline 12 & R. villosa subsp. mollis & Switzerland & 4 \\
\hline 17 & R. villosa subsp. mollis & Switzerland & 4 \\
\hline 52 & R. wichurana Crép. & - & 2 \\
\hline 36 & R. wichurana Crép. & - & 2 \\
\hline 38 & R. woodsii Lindl. & - & 2 \\
\hline 32 & $\begin{array}{l}\text { R. } \times \text { irregularis Déségl. \& } \\
\text { Guillon }^{\S}\end{array}$ & Netherlands & Unknown \\
\hline
\end{tabular}

${ }^{\pi}$ Accessions 1-19 were from Samiei et al. (2010). Accessions 11-35 were also used in Koopman et al. (2008).

$* R$. multiflora 'hybrid 117 ' is a diploid rose from a cross between Rosa multiflora and an unknown garden rose.

${ }^{\S} R$. $\times$ irregularis is morphologically intermediate between $R$. arvenis and R. canina (Vander Mijnsbrugge et al., 2010). 
bromophenol blue, and denatured for $5 \min$ at $80^{\circ} \mathrm{C}$ before being electrophoresed in standard $6 \%(\mathrm{w} / \mathrm{v})$ polyacrylamide denaturing-sequencing gels at $110 \mathrm{~W}$. The gels were silver-stained using the Silver Sequence DNA Sequencing System (Promega, Leiden, The Netherlands). For size estimation, a sequencing reaction on pGEM-3Zf(+), using the pUC/M13 forward 24-mer primer (Promega), accompanied the samples. Rc06 produced clear bands without stutter or shadow bands (quality 1, according to Smulders et al., 1997).

\section{Allele sequencing}

Individual alleles amplified from the 55 Rosa accessions were cut-out from the polyacrylamide gel using a razor blade and re-amplified using the same PCR conditions as for amplification of the SSR. Approx. $50 \mathrm{ng}$ of each PCR product was used for sequencing in $4 \mu \mathrm{l} 5 \mathrm{x}$ sequencing buffer, $0.5 \mu 110 \mathrm{pmol} \mathrm{ml}^{-1}$ forward or reverse primer, in a total volume of $10 \mu \mathrm{l}$. The PCR programme consisted of 25 cycles of $20 \mathrm{~s}$ at $94^{\circ} \mathrm{C}, 50^{\circ} \mathrm{C}$ for $15 \mathrm{~s}$, and $60^{\circ} \mathrm{C}$ for $1 \mathrm{~min}$. The PCR products were sequenced directly on an ABI 3730 instrument (Life Technologies, Carlsbad, CA, USA).

\section{Data analysis}

After removal of the primer regions, all DNA sequences were aligned using Seqman (Burland, 2000) Version 8.10 (DNASTAR) and corrected manually. Haplotypes were defined manually, based on SNPs in the flanking regions. Subsequently, we determined which haplotype (or haplotypes) had been amplified in each accession. Some SNP-based haplotypes occurred in variants with a range of microsatellite repeat lengths. Some SNPs existed in the repeat region. The set of flanking SNP haplotypes, as well as the set of haplotypes based on all SNPs, were analysed using MEGA 5.04 software (Tamura et al., 2011) employing maximum parsimony (MP) clustering with 1,000 permutations. For this, the alleles were trimmed to the same length.

\section{RESULTS AND DISCUSSION}

SNPSTR development

In a preliminary analysis, and in contrast to Chatrou et al. (2009), we found that normal STR markers, including several with known map positions (Spiller et al., 2011; Koning-Boucoiran et al., 2012), had flanking sequences that were too short to contain sufficient SNP polymorphism outside the microsatellite repeat. This remained so, even when we redesigned the primers to amplify as much flanking sequence as possible, based on the genomic sequence available for the STR markers. We therefore performed a new STR enrichment, without size-limitation for the clones. This resulted in a single long, polymorphic STRSNP marker, Rc06 (EMBL/GenBank Accession Number HE608872).

\section{SNPs flanking the STR}

When we amplified and directly sequenced alleles of Rc06, most diploid species had only one allele, while the polyploid species had two-to-five different alleles. In total, 61 high quality sequences were obtained from the 55 Rosa accessions.

After aligning the resulting sequences, we focussed on the occurrence of SNPs. In total, 12 SNPs were detected in the regions flanking the repeat (Table II). They occurred in 18 different combinations (haplotypes; Table II). Of these, nine haplotypes were found in only one species, seven in two or three species, and two (H1 and $\mathrm{H} 15)$ in as many as 12 different species.

The sharing of identical SNP haplotypes deserves closer attention. Haplotype H1 was found in diploid species from the sub-Sections Cinnamomeae ( $R$. majalis, $R$. rugosa, $R$. woodsii, and $R$. acicularis) and Carolineae ( $R$. nitida), together with polyploid species from the subSections Caninae, Rosa, Rubiginae, Pimpinellifoliae, and Vestitae, suggesting that these diploid species had contributed to the tetraploid and pentaploid species. Halotype $\mathrm{H} 15$ was present in diploid $R$. multiflora, while $R$. arvensis contained halotype $\mathrm{H} 7$, which was only one SNP different from H15. Both species are from the Section Synstylae. All other accessions that had halotype H15 sequences were from polyploid accessions from most of the Sections in the genus Rosa.

These results may indicate the contribution of diploid species of Section Synstylae to various polyploid species of these Sections and sub-Sections. Of the haplotypes that we found less frequently, $\mathrm{H} 4$ was present in the

TABLE II

Overview of the 18 haplotypes based on the 12 SNPs that flanked the STR and the diploid (underlined) or polyploid species in which they were found

\begin{tabular}{|c|c|c|}
\hline Haplotype & $\mathrm{SNP}^{\ddagger}$ & Species (followed by a number, if more than one allele was sequenced) \\
\hline 1 & CTCAGGTATTTA & 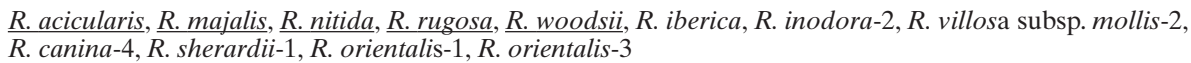 \\
\hline 2 & TCCAGATCTTTG & $R$. foetida'double'-1, R. foetida'double'-3, R. hemisphaerica \\
\hline 3 & TCCAGACCTTTG & R. foetida 'double'-2 \\
\hline 4 & CTCAGGTCTTTA & R. pendulina, $R$. pimpinellifolia \\
\hline 5 & CTCAGGTATTTG & R. blanda \\
\hline 6 & CTCAGGTCTTTG & R. sertata \\
\hline 7 & CTCAGATCTACG & R. arvensis \\
\hline 8 & CCCGCATCTATG & R. chinensis, $R$. moschata, $R$. canina -1 \\
\hline 9 & CCCGCATCCATG & R. tomentella \\
\hline 10 & CCCAGATCTTCG & R. inodora-1 \\
\hline 11 & CCCAGATCTATG & R. wichurana,$\underline{R}$. multiflora 'hybrid 117 ', R. canina-3 \\
\hline 12 & CCCAGATCTACA & R. villosa subsp. mollis-3, R. micrantha- $2, R$. caesia \\
\hline 13 & CCCAGATCTTTG & R. foetida \\
\hline 14 & CCCAGATCTATA & R. corymbifera- 2, R. sherardii- 2 \\
\hline 15 & CCCAGATCTACG & $\begin{array}{l}\text { R. multiflora, } R . \text { micrantha- } 1, R . \text { damascena, } R . \text { dumalis, } R . \text { villosa subsp. mollis }-1, R \text {. sherardii-3, } \\
R . \text { columnifera, } R . \times \text { irregularis, } R . \text { rubiginosa, } R \text {. spinosissima, } R \text {. orientalis- } 2, R \text {. canina- } 2\end{array}$ \\
\hline 16 & CCAAGATCTTTG & $\underline{R}$ sericea,$\underline{R}$. sericea subsp.omeiensis, $\underline{R}$. hugonis \\
\hline 17 & CCAAGATCTATG & R. roxburgii \\
\hline 18 & CCCGGATCTATA & R. corymbifera-1 \\
\hline
\end{tabular}

${ }^{\ddagger}$ For SNP positions, see Figure 1 . 
diploid $R$. pendulina and the tetraploid $R$. pimpinellifolia, H8 was shared between the diploid $R$. chinensis and $R$. moschata and the pentaploid $R$. canina, while H11 was shared between the diploid $R$. multiflora and $R$. wichurana (both from sub-Section Synstylae) and $R$. canina.

\section{STR repeat polymorphisms}

The STR was structurally complex, as there were three different polymorphic repeat regions (Figure 1). The first region was a GXT repeat, for which the most frequent repeat length was $(\mathrm{GXT})_{8}$. This repeat existed in three sequence variants (Table III). We detected several copies of SNP haplotype $\mathrm{H} 1$ with a $(\mathrm{GXT})_{4}$ repeat, which was possibly a repeat contraction (deletion) from the more frequent $(\mathrm{GXT})_{8}$ repeat. It occurred in four polyploid species from two Sections: Vestitae ( $R$. sherardii and $R$. villosa subsp. mollis) and Caninae (R. iberica and $R$. orientalis). These polyploid species may have received the allele from an ancestor in one of the diploid species that contained haplotype $\mathrm{H} 1$. The $(\mathrm{GXT})_{4}$ repeat also occurred in SNP haplotypes $\mathrm{H} 2$ and $\mathrm{H} 3$ in $R$. foetida and $\mathrm{H} 15$ in $R$. caesia. As $\mathrm{H} 2$ differred from $\mathrm{H} 1$ in five SNPs, plus the presence of an indel, this probably reflected an independent repeat length reduction. Halotype $\mathrm{H} 3$ was probably derived from $\mathrm{H} 2$ by a single mutation in $R$. foetida. R. foetida also had another unique allele, a length variant of SNP haplotype $\mathrm{H} 2$, with an expansion to $(\mathrm{GXT})_{12}$ in the first repeat.

There was a monomorphic region between the first and second repeat, except for a deletion of $12 \mathrm{nt}$ in one of the two SNP haplotype H1 alleles of $R$. orientalis and $R$. inodora. The second repeat was always $(\mathrm{GXT})_{10}$, but it existed in six sequence variants. These variants appeared to represent independent mutations.

The third region was a $(\mathrm{GXT})_{9}$ repeat, except in $R$. caesia and $R$. corymbifera alleles 1 and 2, in which it was $(\mathrm{GXT})_{6}$ and $(\mathrm{GXT})_{15}$, respectively. A $(\mathrm{GXT})_{6}$ repeat occurred in SNP haplotypes H10, H14, and H18. A $(\mathrm{GXT})_{15}$ repeat was found once in SNP haplotype H12, in $R$. caesia.

In addition to the microsatellite region, there was a 9-bp insertion towards the 3'-end of the amplified allele, present in nine SNP haplotypes and absent in four haplotypes $(\mathrm{H} 1, \mathrm{H} 4$, and $\mathrm{H} 5$, and also in $\mathrm{H} 10$, which was quite different in sequence). Unfortunately, the sequences obtained for five haplotypes were not fulllength; so, for these haplotypes, we do not know whether they did or did not contain the 9-bp insert sequence.

\section{Phenetic relationships among haplotypes}

We could distinguish 11 additional SNPs within the STR region (indicated in bold font in Table III). When these were added to the set of 12 flanking SNPs, to generate a maximum-likelihood (ML) tree (Figure 2), the signals of the SNPs from the repeat region contributed relatively little to the resolution of the dendrogram compared to that of an ML tree based only on flanking SNPs (data not shown). This suggests that the repeat region SNPs were more recent than some of the flanking SNPs.

Bootstrap values in the ML dendrogram were relatively low, probably due to the low number of informative sites. We tentatively distinguished five Groups of related haplotypes, but only haplotype Groups III, IV, and V were supported by somewhat higher bootstrap values (i.e., 70, 71, and 78 of 100 replications, respectively). Group III and Group IV haplotypes were found in species from the Section Pimpinellifoliae. Group III haplotypes were present in the tetraploid $R$. foetida (in various variants, see above) and in R. hemispaerica; while Group IV haplotypes were found in various diploid species from this Section, including $R$. hugonis, plus diploid $R$. roxburgii from the sub-genus Platyrhodon. $R$. roxburgii and $R$. hugonis were also the most similar species in the most parsimonous tree based on the AFLP data in Koopman et al. (2008). Therefore, our data support the conclusions of these authors and those of several others (Matsumoto et al., 1998; Wu et al., 2001; Wissemann and Ritz, 2005; Bruneau et al., 2007) that $R$. roxburgii was incorrectly classified into the separate sub-genus, Plathyrodon. The fact that Section Pimpinellifoliae haplotypes in Group IV were not found in any polyploid species may mean that these species did not contribute to the polyploid Rosa species, or that we did not include the polyploid species concerned. On the other hand, the fact that haplotypes from diploid and polyploid species did not resemble each other closely was consistent with the hypothesis (Matsumoto et al., 2001; Bruneau et al., 2007) that Section Pimpinellifoliae was a polyphyletic group.

Group V included haplotype $\mathrm{H} 1$, plus three other haplotypes. The group contained all haplotypes obtained from the seven diploid species of the Section Cinnamomeae, and a diploid species of the Section Carolineae that was included in this study, as well as haplotypes from various polyploid Sections, notably various species of the Section Caninae.

\section{CONCLUSIONS}

Haplotypes that occurred in polyploid Rosa species were shared with those in diploid Rosa species, indicating that these diploid species may have been involved in the formation of allopolyploid roses with higher ploidy levels. Nevertheless, our study should only be considered as a proof-of-concept, as we did not include a complete set of accessions from all diploid species, and used only a single SNPSTR locus. Multiple accessions per taxon may

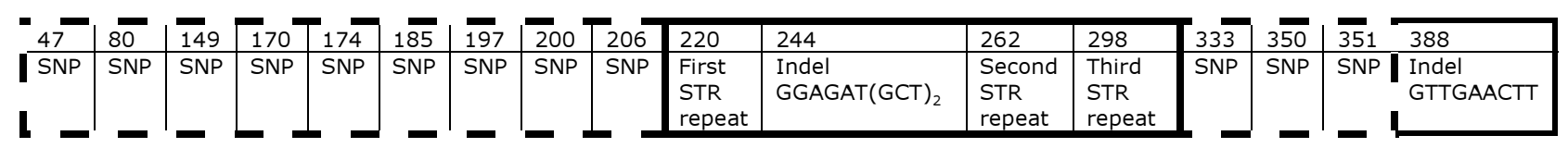




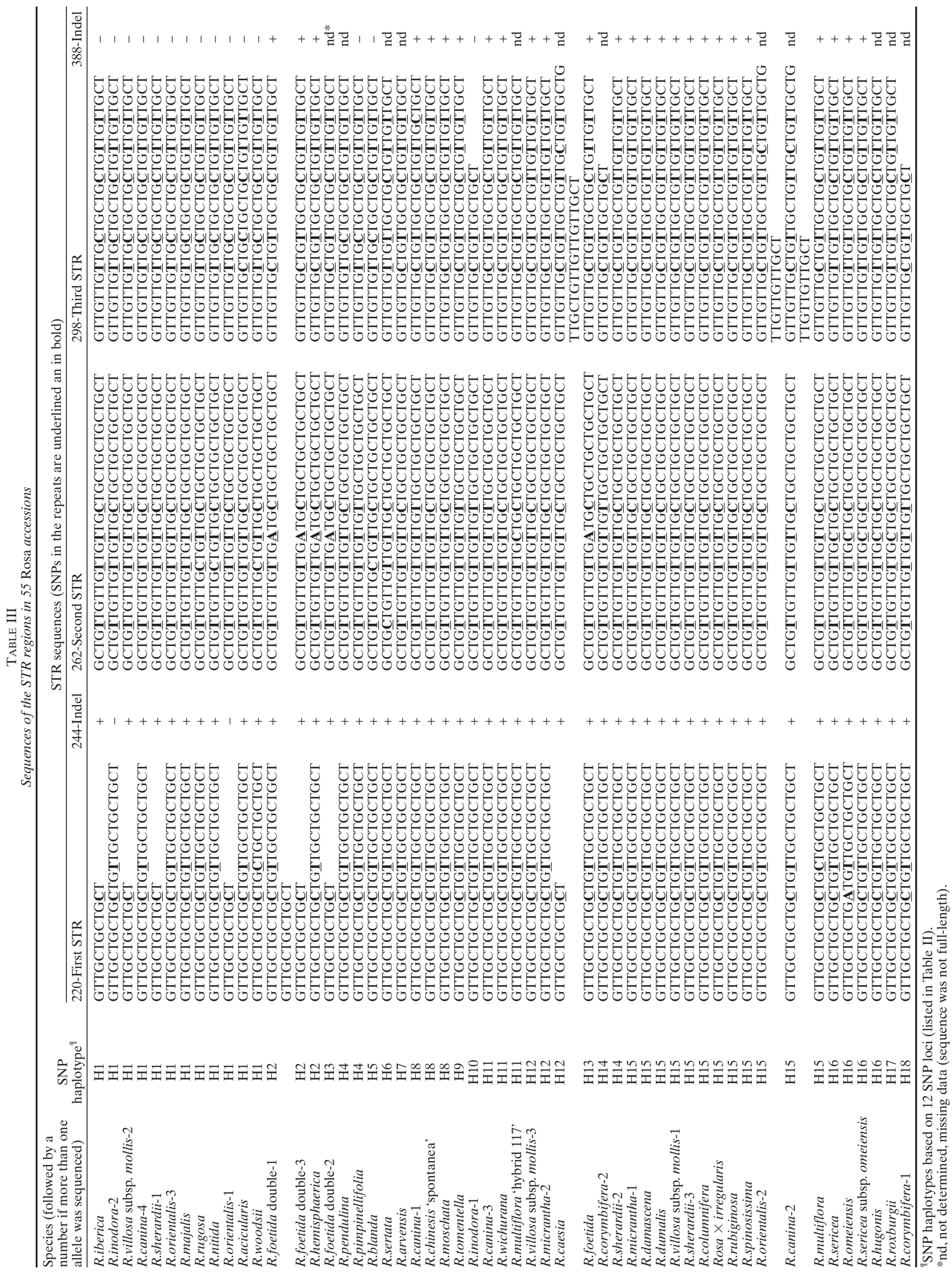



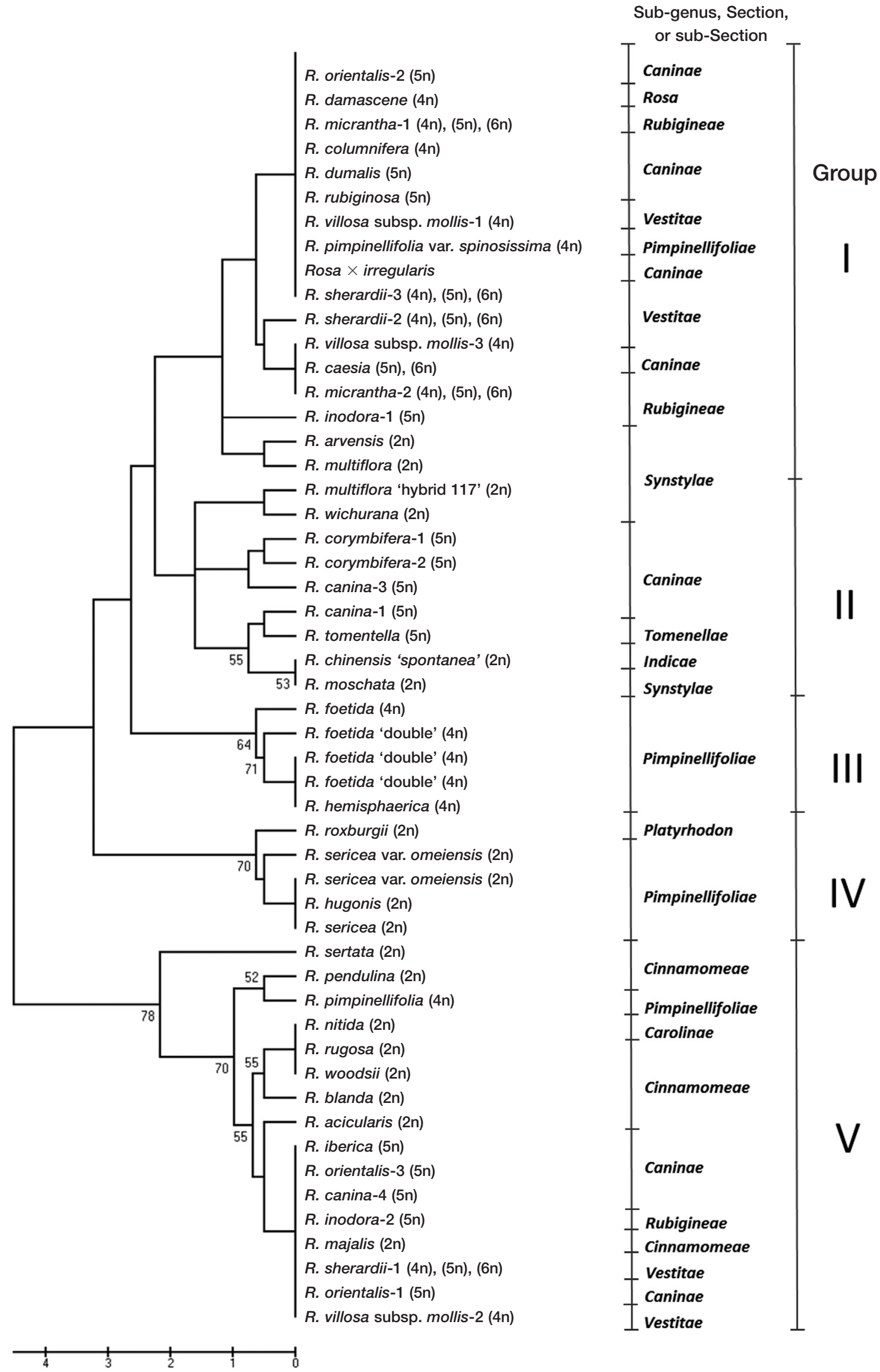

FIG. 2

Maximum-likelihood tree of all haplotypes found in the 55 accessions of Rosa studied here. Haplotypes were based on the 12 SNPs flanking the repeats (Table II) plus the eight SNPs present in the repeat region (Table III). Numbers at each node are bootstrap values based on 1,000 iterations. Only values $\geq 50 \%$ are shown. Ploidy levels are indicated next to the species name. Numbers next to the species name distinguish multiple haplotypes from the same accession. Groups I-V tentatively indicate major Groups of haplotypes. The scale bar indicates substitutions per nucleotide position. 
be necessary if there is heterogeneity in the chromosomal segments present in polyploids. In that case, more loci would have to be included in order to cover the genomes involved. Next-generation sequencing will facilitate this, as it becomes cheaper to generate sequences from a large variety of samples without the need to clone the sequences. It is essential that multiple haplotypes with SNPs are obtained, as only this would generate the necessary resolving power.

This research was supported, in part, by a TTI Green Genetics Grant (Project 'Hyperrose') to Wageningen UR Plant Breeding. We thank Alireza Babaei and Leila Samiei for assistance with the PCRs.

\section{REFERENCES}

Alvarez, A. E., Van De Wiel, C. C. M., Smulders, M. J. M. and Vosman, B. (2001). Use of microsatellites to evaluate genetic diversity and species relationships in the genus Lycopersicon. Theoretical and Applied Genetics, 103, 1283-1292.

Babaei, A., TAbaei-Aghdaei, S. R., Khosh-Khui, M., Omidbaigi, R., Naghavi, M. R., Esselink, G. D. and Smulders, M. J. M. (2007). Microsatellite analysis of Damask rose (Rosa damascena Mill.) accessions from various regions in Iran reveals multiple genotypes. BMC Plant Biology, 10, 12.

Brassac, J., Jakob, S. S. and Blattner, F. R. (2012). Progenitorderivative relationships of Hordeum polyploids (Poaceae, Triticeae) inferred from sequences of TOPO6, a nuclear lowcopy gene region. PLoS ONE, 7, e33808.

Bruneau, A., Starr, J. R. and Joly, S. (2007). Phylogenetic relationships in the genus Rosa: New evidence from chloroplast DNA sequences and an appraisal of current knowledge. Systematic Botany, 32, 366-378.

BuRLAND, T. G. (2000). DNASTAR's Lasergene sequence analysis software. Methods in Molecular Biology, 132, 71-91.

Chatrou, L. W., Escribano, M. P., Viruel, M. A., Maas, J. W. Richardson, J. E. and HormaZA, J. I. (2009). Flanking regions of monomorphic microsatellite loci provide a new source of data for plant species-level phylogenetics. Molecular Phylogenetics and Evolution, 53, 726-733.

De Cock, K., Van Der Mijnsbrugge, K., Breyne, P., Van BockStaele, E. and VAn Slycken, J. (2008). Morphological and AFLP-based differentiation within the taxonomical complex section Caninae (subgenus Rosa). Annals of Botany, 102, 685-697.

Esselink, G. D., Smulders, M. J. M. and Vosman, B. (2003). Identification of cut rose (Rosa hybrida) and rootstock varieties using robust sequence tagged microsatellite site markers. Theoretical and Applied Genetics, 106, 277-286.

Griffin, P. A., Robin, C. and HoffmAnn, A. A. (2011). A next-generation sequencing method for overcoming the multiple gene copy problem in polyploid phylogenetics, applied to Poa grasses. BMC Biology, 9, 19.

Joly, S., Starr, J. R., Lewis, W. H. and Bruneau, A. (2006). Polyploid and hybrid evolution in roses east of the Rocky Mountains. American Journal of Botany, 93, 412-425.

Koning-Boucoiran, C. F. S., Gitonga, V. W., Yan, Z., Dolstra, O., VAn Der Linden, C. G., Van Der Schoot, J., Uenk, G. E., Verlinden, K., Smulders, M. J. M., Krens, F. A. and MaliepaARD, C. (2012). The mode of inheritance in tetraploid cut roses. Theoretical and Applied Genetics, 125, 591-607 .

Koopman, W. J. M., Wissemann, V., De Cock, K., Van Huylenbroeck, J., De Riek, J., Sabatino, G. J. H., Visser, D., Vosman, B., Ritz, C. M., Maes, B., Werlemark, G., Nybom, H., Debener, T., LINDE, M. and SMULDERS, M. J. M. (2008). AFLP markers as a tool to reconstruct complex relationships: A case study in Rosa (Rosaceae). American Journal of Botany, 95, 353-366.

Leus, L., Jeanneteau, F., Van Huylenbroeck, J., Van BockStAele, E. and De RieK, J. (2004). Molecular evaluation of a collection of rose species and cultivars by AFLP, ITS, $r b c L$ and matK. Acta Horticulturae, 651, 141-147.

Matsumoto, S., Kouchi, M., YAbUKi, J., Kusunoki, M., UedA, Y. and FUKUI, H. (1998). Phylogenetic analyses of the genus Rosa using the matK sequence: Molecular evidence for the narrow genetic background of modern roses. Scientia Horticulturae, 77, 73-82.

Matsumoto, S., Nishio, H., Ueda, Y. and Fukui, H. (2001). Phylogenetic analyses of the genus Rosa: Polyphyly of the Section Pimpinellifoliae and the origin of Rosa $\times$ fortuniana Lindl. Acta Horticulturae, 547, 357-363.
Mountain, J. L., Knight, A., Jobin, M., GignouX, C., Miller, A., LIN, A. A. and UNDERHILL, P. A. (2002). SNPSTRs: Empirically derived, rapidly typed, autosomal haplotypes for inference of population history and mutational processes. Genome Research, 12, 1766-1772.

PAyseur, B. A. and CutTer, A. D. (2006). Integrating patterns of polymorphism at SNPs and STRs. Trends in Genetics, 22, 424-429.

Ramakrishnan, U. and Mountain, J. L. (2004). Precision and accuracy of divergence time estimates from STR and SNPSTR variation. Molecular Biology and Evolution, 21, 1960-1971.

Rehder, A. (1940) Manual of Cultivated Trees and Shrubs. 2nd Edition. McMillan Co., New York, NY, USA. 996 pp.

Samiei, L., Naderi, R., Khalighi, A., Bushehri, A. A., Mozaffarian, V., EsselinK, D. and Smulders, M. J. M. (2009). In search of genetic diversity in Rosa foetida Herrmann in Iran. Acta Horticulturae, 836, 25-30.

Samiei, L., Naderi, R., Khalighi, A., Shahnejat-Bushehri, A. A., Mozaffarian, V., EsselinK, G. D., KaZempour Osaloo, S. and SMULDERS, M. J. M. (2010). Genetic diversity and genetic similarities between Iranian rose species. Journal of Horticultural Science \& Biotechnology, 85, 231-237.

SCARIOT, V., AKKAK, A. and BotTA, R. (2006). Characterization and genetic relationships of wild species and old garden roses based on microsatellite analysis. Journal of the American Society for Horticultural Science, 131, 66-73.

Smulders, M. J. M., Bredemeijer, G., Rus-KortekaAs, W., Arens, P. and Vosman, B. (1997). Use of short microsatellites from database sequences to generate polymorphisms among Lycopersicon esculentum cultivars and accessions of other Lycopersicon species. Theoretical and Applied Genetics, 94, 264-272.

SMUlders, M. J. M., EsSelink, D., Voorrips, R. E. and Vosman, B. (2009). Analysis of a database of DNA profiles of 734 hybrid tea rose varieties. Acta Horticulturae, 836, 169-174.

Smulders, M. J. M., Arens, P., Koning-Boucoiran, C., Gitonga, V., Krens, F., Atanassov, A., Atanassov, I., Rusanov, K., Bendahmane, M., Dubois, A., Raymond, O., Caissard, J. C., Baudino, S., Crespel, L., Gudin, S., Ricci, S. C., Kovatcheva, N., Van Huylenbroeck, J., Leus, L., Wissemann, V., Zimmermann, H., Hensen, I., Werlemark, G. and Nybom, H. (2011). Rosa. In: Wild Crop Relatives: Genomic and Breeding Resources Plantation and Ornamental Crops. (Kole, C., Ed.). SpringerVerlag, Berlin, Heidelberg, Germany. 243-275.

Sorenson, M. D. and DaCosta, J. M. (2011). Genotyping HapSTR loci: phase determination from direct sequencing of PCR products. Molecular Ecology Resources, 11, 1068-1075.

Spiller, M., Linde, M., Hibrand-Saint Oyant, L., Tsai, C.-J., ByrNe, D. H., SMulders, M. J. M., Foucher, F. and Debener, T. (2011). Towards a unified genetic map of diploid rose. Theoretical and Applied Genetics, 122, 489-500.

Tamura, K., Peterson, D., Peterson, N., Stecher, G., Nei, M. and KuMAR, S. (2011). MEGA5: Molecular evolutionary genetics analysis using maximum likelihood, evolutionary distance, and maximum parsimony methods. Molecular Biology and Evolution, 28, 2731-2739.

Van Der Mijnsbrugge, K., De Cock, K., Cox, K. and Breyne, P. (2010). Conservation measures for Rosa arvensis Huds. in Flanders (Belgium) based on congruent genetic and phenotypic population differentiation. Conservation Genetics, 11, 2243-2253. 
Wissemann, V. (2003). Conventional taxonomy of wild roses. In: Encyclopedia of Rose Science. (Roberts, A., Debener, T. and Gudin, S., Eds.). Elsevier, London, UK. 111-117.

Wissemann, V. and Ritz, C. M. (2005). The genus Rosa (Rosoideae, Rosaceae) revisited: molecular analysis of $n r I T S-1$ and atpB$r b c L$ intergenic spacer (IGS) versus conventional taxonomy. Botanical Journal of the Linnean Society, 147, 275-290.
Wu, S., Ueda, Y., He, H., Nishihara, S. and Matsumoto, S. (2000). Phylogenetic analysis of Japanese Rosa species using matK sequences. Breeding Science, 50, 275-281.

Wu, S., Ueda, Y., Nishihara, S. and Matsumoto, S. (2001). Phylogenetic analysis of Japanese Rosa species using DNA sequences of nuclear ribosomal internal transcribed spacers (ITS). Journal of Horticultural Science \& Biotechnology, 76, 127-132. 